\title{
Gold nanoparticles administration induced prominent inflammatory, central vein intima disruption, fatty change and Kupffer cells hyperplasia
}

\author{
Mohamed Anwar K Abdelhalim ${ }^{1 *}$ and Bashir M Jarrar ${ }^{2}$
}

\begin{abstract}
Background: Advances in nanotechnology have identified promising candidates for many biological, biomedical and biomedicine applications. They are being increasingly exploited for medical uses and other industrial applications. The aim of the present study was to investigate the effects of administration of gold nanoparticles (GNPs) on inflammatory cells infiltration, central vein intima disruption, fatty change, and Kupffer cells hyperplasia in the hepatic tissue in an attempt to cover and understand the toxicity and the potential threat of their therapeutic and diagnostic use.

Methods: A total of 70 healthy male Wistar-Kyoto rats were exposed to GNPs received 50 or $100 \mu$ l of GNPs infusion of 10, 20 and $50 \mathrm{~nm}$ GNPs for 3 or 7 days. Animals were randomly divided into groups, 12 GNPs-treated rats groups and one control group (NG). Groups 1, 2 and 3 received infusion of $50 \mu$ GNPs of size $10 \mathrm{~nm}$ (3 or 7 days), size $20 \mathrm{~nm}$ (3 or 7 days) and $50 \mathrm{~nm}$ (3 or 7 days), respectively; while groups 4, 5 and 6 received infusion of $100 \mu \mathrm{l} \mathrm{GNPs}$ of size $10 \mathrm{~nm}$, size $20 \mathrm{~nm}$ and $50 \mathrm{~nm}$, respectively.

Results: In comparison with respective control rats, exposure to GNPs doses has produced alterations in the hepatocytes, portal triads and sinusoids. The alterations in the hepatocytes were mainly vacuolar to hydropic degeneration, cytopasmic hyaline vacuolation, polymorphism, binucleation, karyopyknosis, karyolysis, karyorrhexis and necrosis. In addition, inflammatory cell infiltration, Kupffer cells hyperplasia, central veins intima disruption, hepatic strands dilatation and occasional fatty change together with a loss of normal architechiture of hepatic strands were also seen.

Conclusions: The alterations induced by the administration of GNPs were size-dependent with smaller ones induced more affects and related with time exposure of GNPs. These alterations might be an indication of injured hepatocytes due to GNPs toxicity that became unable to deal with the accumulated residues resulting from metabolic and structural disturbances caused by these NPs. These histological alterations may suggest that GNPs interact with proteins and enzymes of the hepatic tissue interfering with the antioxidant defense mechanism and leading to reactive oxygen species (ROS) generation which in turn may induce stress in the hepatocytes to undergo necrosis.
\end{abstract}

Keywords: gold nanoparticles, size, hepatic tissue, histology, inflammatory, fatty changes, nanotoxicity, rats

\footnotetext{
* Correspondence: abdelhalimmak@yahoo.com

'Department of Physics and Astronomy, College of Science, King Saud

University, Saudi Arabia

Full list of author information is available at the end of the article
} 


\section{Introduction}

In vivo studies in rats exposed to aerosols of GNPs revealed that the NPs were rapidly taken into the system with the highest accumulation in the lungs, aorta, esophagus and olfactory bulb [1]. Moreover, particles of nano-dimension are believed to be more biologically reactive than their bulk counter parts due to their small size and larger surface area to volume ratio $[1,2]$.

Gold in its bulk form has long been considered an inert, noble metal with some therapeutic and even medicinal value hence GNPs are thought also to be relatively non-cytotoxic [3]. Yet there are differing reports of the extent of the toxic nature of these particles owing to the different modifications of the GNPs, surface functional attachments and shape and diameter size of the nanospheres $[4,5]$. Moreover, the metallic nature of the metal derived NPs and the presence of transition metals encourages the production of reactive oxygen species (ROS) leading to oxidative stress [6,7].

Although some scientists consider NPs as nontoxic [8-10], other cellular mechanisms such as cell signaling and other normal cellular functions may be disrupted and are currently undergoing further investigation $[11,12]$. The toxicity of NPs is being addressed by a number of standardized approaches with in vitro, in vivo as well as detailed genomic or biodistribution studies [12].

It has been shown that NPs may produce in vitro toxicity in some cell-based assays, but not in others. This may be a result of interference with the chemical probes, differences in the innate response of particular cell types, or other factors [13]. In addition, GNPs are used as carriers for the delivery of drugs and genes [14].

GNPs can easily enter cells and the demonstration that amine and thiol groups bind strongly to GNP has enabled their surface modification with amino acids and proteins for biomedical applications $[15,16]$.

The histological and histochemical characterization in the hepatic tissues due to GNPs has not been documented and identified. In the present study, an attempt has been made to characterize the possible histological alterations in the hepatic tissues after the administration of GNPs and, if so, whether are related to the size of these GNPs and the time of exposure.

The present study was carried out to investigate particle-size and administration period effects of GNPs on inflammatory, central vein intima, fatty and Kupffer cells hyperplasia disruption in an attempt to cover and understand the toxicity and potential threat of their therapeutic and diagnostic use.

\section{Materials and methods}

A total of 70 healthy male Wistar-Kyoto rats obtained from the Laboratory Animal Center (College of Pharmacy, King Saud University, Saudi Arabia). The rats nearly of the same age (12 weeks old) and weighing 220-240 g of King Saud University colony were used. Animals were randomly divided into groups, 12 GNPs-treated rats groups and one control group (NG). Following a period of stabilization (7 days), 10, 20 and $50 \mathrm{~nm}$ GNPs were administered intraperitonealy at the rate for 3 or 7 days as follows: Group 1: received infusion of $50 \mu \mathrm{l}$ GNPs of size $10 \mathrm{~nm}$ for 3 or 7 days $(n=10)$; Group 2: received infusion of 50 $\mu \mathrm{l}$ GNPs of size $20 \mathrm{~nm}$ for 3 or 7 days $(\mathrm{n}=10)$; Group 3: received infusion of $50 \mu \mathrm{l}$ GNPs of size 50 $\mathrm{nm}$ for 3 or 7 days $(\mathrm{n}=10)$; Group 4: received infusion of $100 \mu \mathrm{l}$ GNPs of size $10 \mathrm{~nm}$ for 3 or 7 days; (n = 10); Group 5: received infusion of $100 \mu \mathrm{l}$ GNPs of size $20 \mathrm{~nm}$ for 3 or 7 days $(\mathrm{n}=10)$; Group 6: received infusion of $100 \mu \mathrm{l}$ GNPs of size $50 \mathrm{~nm}$ for 3 or 7 days; $(\mathrm{n}=10)$; Control group: received no gold nanoparticles $(n=10)$.

The rats were maintained on standard laboratory rodent diet pellets and housed in humidity and temperature-controlled ventilated cages on a $12 \mathrm{~h}$ day/night cycle. All experiments were conducted in accordance with the guidelines approved by King Saud University Local Animal Care and Use Committee.

Fresh portions of the lateral lobes of the liver from each rat were cut rapidly, fixed in neutral buffered formalin (10\%), then dehydrated, with grades of ethanol (70, 80, 90, 95 and 100\%). Dehydration was then followed by clearing the samples in 2 changes of xylene. Samples were then impregnated with 2 changes of molten paraffin wax, then embedded and blocked out. Paraffin sections (4-5 um) were stained with hematoxylin and eosin (the conventional histological and stain) according to Pearse [17].

Stained sections of control and treated rats were examined for alterations in the hepatocytes for the presence of inflammatory, fatty change and Kupffer cells hyperplasia and necrosis.

\section{Results and Discussions}

\section{Size and morphology of different gold nanoparticles}

The 10 and $20 \mathrm{~nm}$ GNPs show spherical shape while the $50 \mathrm{~nm}$ GNPs show hexagonal shape. The mean size for GNPs was calculated from the images taken by the transmission electron microscope (TEM): The $10 \mathrm{~nm}$ GNPs was of mean size $9.45 \pm 1.33 \mathrm{~nm}, 20 \mathrm{~nm}$ GNPs was of mean size $20.18 \pm 1.80$ and the $50 \mathrm{~nm}$ GNPs was of mean size $50.73 \pm 3.58$.

\section{Histological alterations}

No mortality occurred in any of the experimental groups of the present investigation, and no alterations were observed in the appearance and behavior of GNPs treated rats in comparison with the control ones. 
In comparison with the control group, the following histological alterations were detected in the liver of GNPs treated rats. These alterations were:

1) Hepatocytes exhibited cloudy swelling with pale cytoplasm and poorly delineated and displaced nuclei in all GNPs treated rats. This ballooning degeneration was more prominent with $100 \mu \mathrm{l}$ dose than $50 \mu \mathrm{l}$ one and with $10 \mathrm{~nm}$ size particles than the larger ones as shown in Figure 1. This swelling might be exhibited as a result of disturbances of membranes function that lead to massive influx of water and $\mathrm{Na}^{+}$due to GNPS effects. Cellular swelling might be accompanied by leakage of lysosomal hydrolytic enzymes that lead to cytoplasmic degeneration and macromolecular crowding [18].

The vacuolated swelling of the cytoplasm of the hepatocytes of the GNPs treated rats might indicate acute and subacute liver injury induced by these NPs. Variable nuclei sizes were observed in some hepatocytes. This change became apparent after 7 days of $50 \mathrm{~nm}$ GNPs administration.

2) The sinusoidal Kupffer cells became prominent and increased in number due to GNPs exposure. This change was more prominent at $10 \mathrm{~nm}$ GNPs with dose of $100 \mu \mathrm{l}$ than $20 \mathrm{~nm}$ and $50 \mathrm{~nm}$ GNPS and more after 7 days of administration than rats exposed to GNPs for 3 days as shown in Figure 2. Kupffer cells activation might indicate that GNPs activate the phagocytic activity of the sinusoidal cells by increasing the number of Kupffte cells to help in removing the accumulated GNPs where lysosomes are involved in the intracellular breakdown into small metabolic products. The produced Kupffer cells hyperplasia might be correlated with the amount of injurious to the hepatic tissue induced by GNPs intoxication and represents a defense mechanism

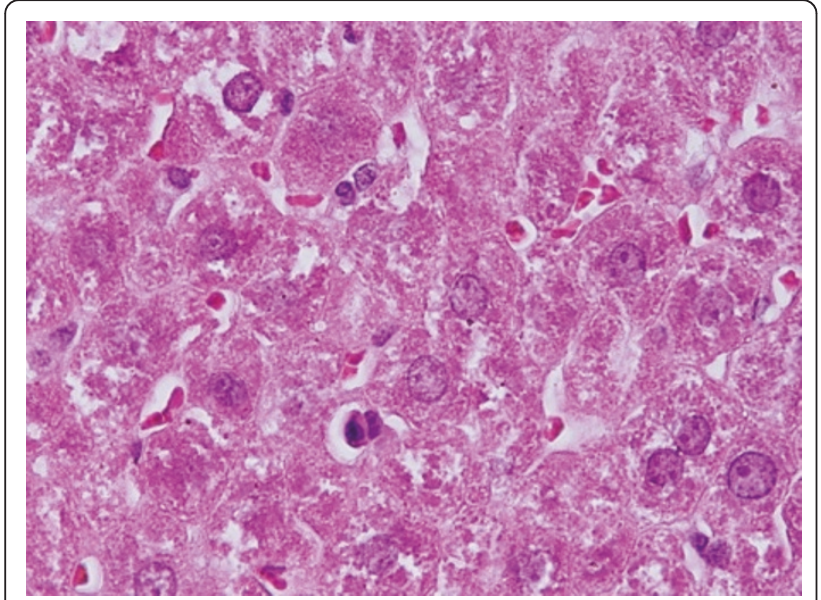

Figure $1 \mathrm{GNPs}$-treated rat received $50 \mu \mathrm{l}$ of $10 \mathrm{~nm}$ particles for 3 days demonstrating hepatocytes cloudy swelling.

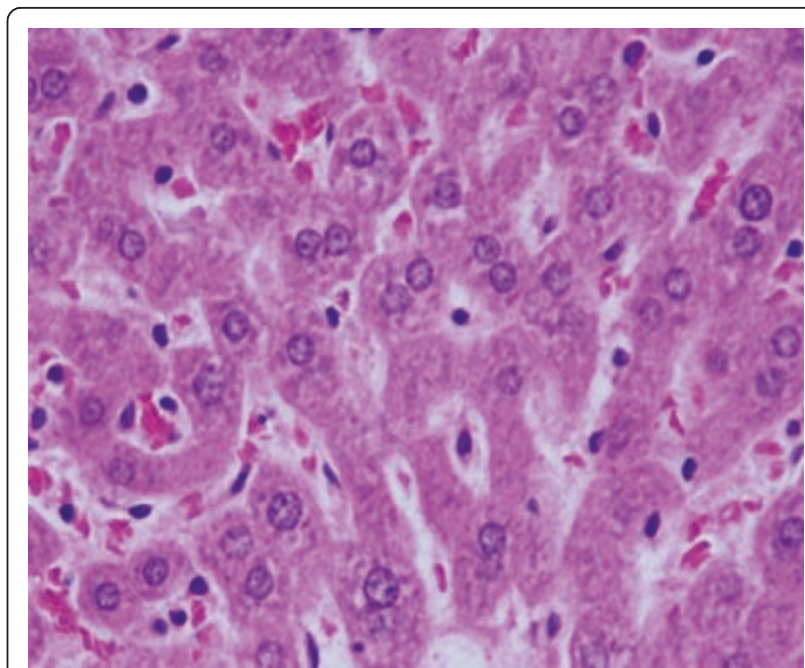

Figure 2 GNPs-treated rat received $50 \mu \mathrm{l}$ of $10 \mathrm{~nm}$ particles for 7 days demonstrating Kupffer cells hyperplasia.

of detoxification. Kupffer cell hyperplasia is contributed to hepatic oxidative stress [19].

3) Sporadic spotty well-defined necrosis was noticed in some hepatocytes of GNPs treated rats as shown in Figure 3. The insulted cells exhibited highly eosinophilic amorphous cytoplasm with occasional apoptotic characterization. This alteration was detected in the liver of rats exposed to $10 \mathrm{~nm}$ size particles and to lesser extent with $20 \mathrm{~nm}$ particles but was not seen with those exposed to $50 \mathrm{~nm}$ size particles. Apoptic alteration might be followed by organelles swelling, specially mitochondria, endoplasmic reticulum and rupture of lysosomes which might lead to amorphous eosinophilic cytoplasm as an initial sign in the sequence of hepatocytes necrosis before shrinking and dissolution of nuclei

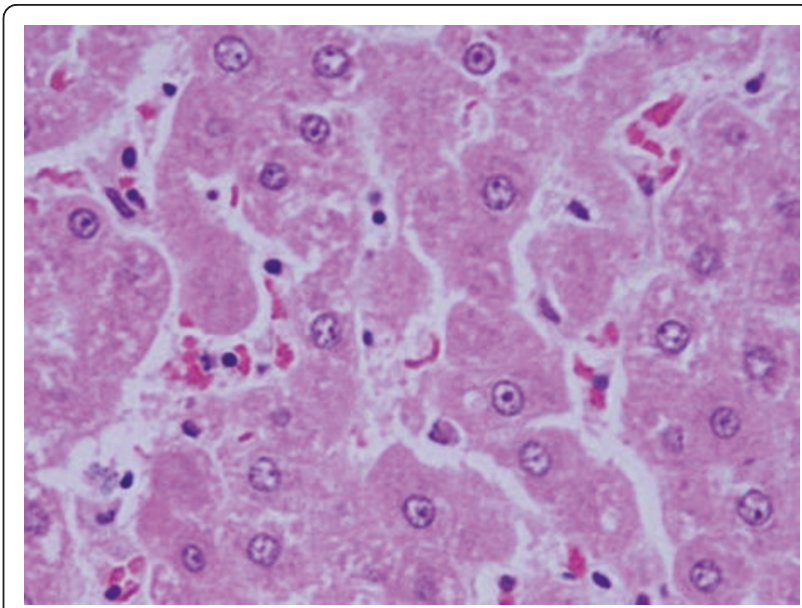

Figure 3 GNPs-treated rat received $50 \mu \mathrm{l}$ of $10 \mathrm{~nm}$ particles for 3 days demonstrating necrotic hepatocytes. 
[20]. The seen hepatocytes necrosis due to GNPs exposure might indicate oxidative stress on these cells by glutathione depletion.

4) Inflammatory cells infiltration was seen in the portal triads and the perioral zones of GNPs treated rats. The infiltrate cells were mainly lymphocytes and plasma cells as shown in Figure 4. This infiltration was more prominent after 7 days of administration and in rats received $100 \mu \mathrm{l}$ than those received $50 \mu \mathrm{l}$. The appearance of inflammatory cells in the hepatic tissue may suggest that GNPs could interact with proteins and enzymes of the hepatic interstitial tissue interfering with the antioxidant defense mechanism and leading to reactive oxygen species (ROS) generation which in turn may imitate an inflammatory response [21].

GNPs were consistently more strongly oxidizing as evidenced by lipid peroxidation as well as decreased neutral red retention time (NRRT) and numbers of thiol-containing proteins evident in electrophoretic separations. Cadmium may displace iron or copper from metalloproteins leading to oxidative stress via the Fenton reaction [22].

It has been reported that $5 \mathrm{~nm}$ GNPs caused significantly greater oxidative stress and cytotoxicity effects than larger ones [23-25]. The $5 \mathrm{~nm}$ GNPs have shown to catalyze nitric oxide (NO) production from endogenous S-nitroso adducts with thiol groups in blood serum. NO reacts rapidly with superoxide producing peroxynitrite (ONOO-) which can interact with lipids, DNA, and proteins via direct oxidative reactions or via indirect radical-mediated damage [24]. ROS production could result from the proportionately high surface area of GNPs used in this investigation [26,27].

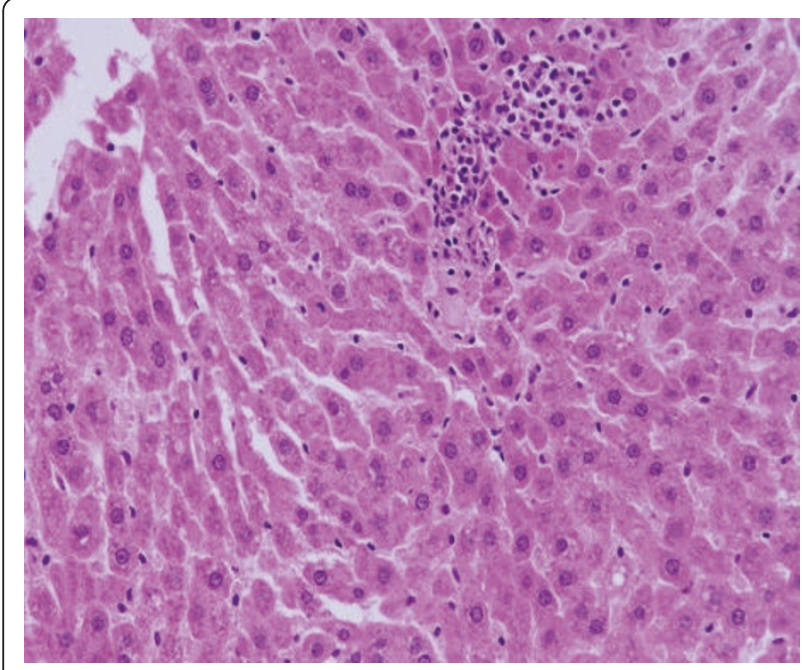

Figure 4 GNPs-treated rat received $100 \mu \mathrm{l}$ of $10 \mathrm{~nm}$ particles for 3 days demonstrating inflammatory cell infiltration.
5) Fatty change was observed in some swelling hepatocytes of rats exposed to $100 \mu \mathrm{l}$ of $10 \mathrm{~nm}$ GNPs and to lesser extent in the ones exposed to larger particles. This hepatic liposis was more prominent in rat exposed to GNPs for 7 days than those received the treatment for 3 days as shown in Figure 5. Hepatocytes fatty change might be due to lipid peroxidation that leads to rough endoplasmic damage and detachment of the cytoplasmic lipoprotein which indicate abnormal fat metabolism [22,25-27]. The seen hepatocytes abnormal retention of lipids in the present investigation induced by GNPs might indicate toxic injury to liver in the form of hepatocytes liposis by these particles.

6) The central veins of the hepatic tissue of rats received 10 and $20 \mathrm{~nm}$ GNPs showed disruption of their intima as shown in Figure 6. Less disruption was observed in rats exposed to $50 \mathrm{~nm}$ GNPs while more damage was detected after 7 days than 3 days of GNPs exposure. This alteration might indicate endothelial damage and vascular stress by GNPs exposure.

None of the above alterations were observed in the liver of any member of the control group.

Some hepatocytes of rats received $50 \mathrm{~nm}$ GNPs showed nucleoli disappearance. This nuclear damage was more prominent after 7 days of exposure to GNPs. Karyorrhexis is a sort of destructive fragmentation of the nucleus processed by pyknosis and followed by karyolysis. Karyolysis is the complete dissolution of the chromatin matter of a dying cell.

Binucleation and to lesser extent polynucleation were observed in GNPs treated rats. Binucleation represents a consequence of cell injury and is a sort of chromosomes hyperplasia which is usually seen in regenerating cells.

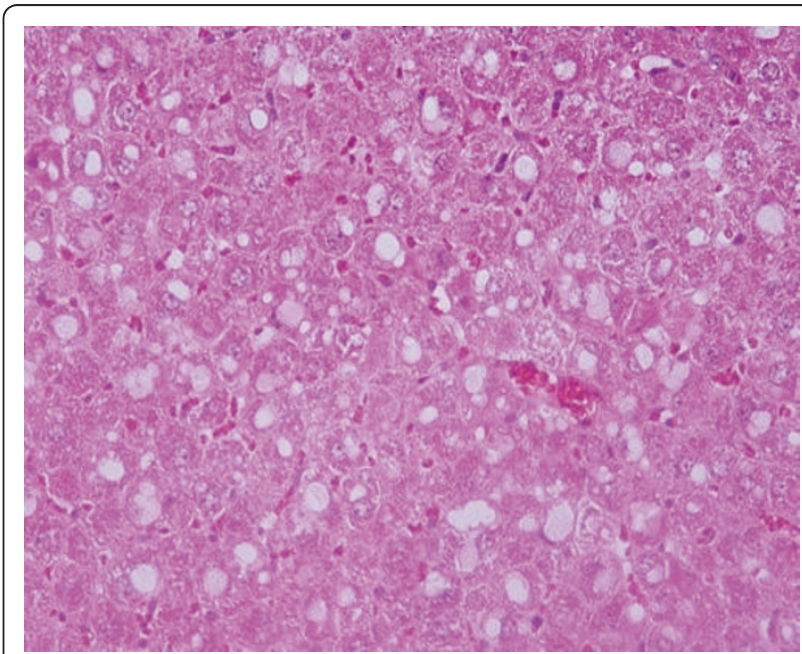

Figure 5 GNPs-treated rat received $100 \mu \mathrm{l}$ of $10 \mathrm{~nm}$ particles for 7 days demonstrating hepatic fatty degeneration. 


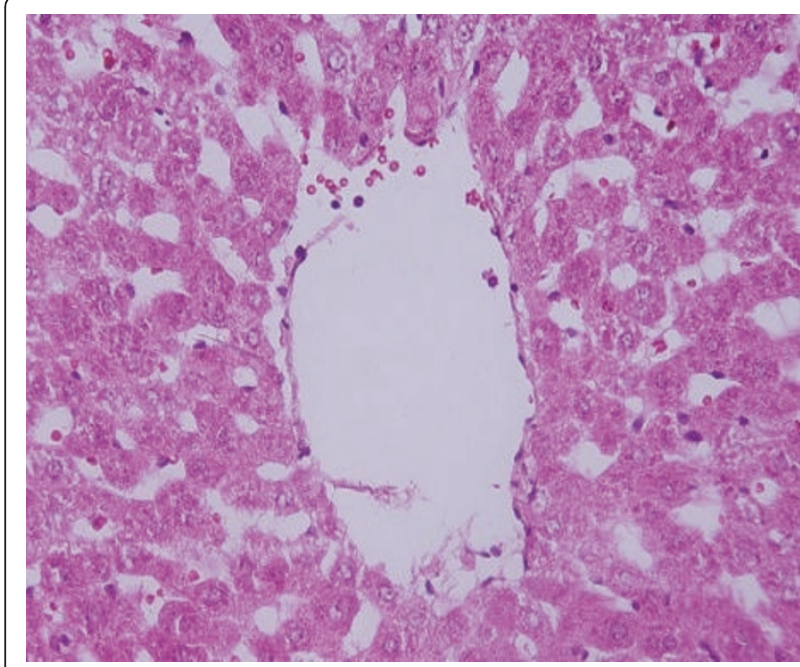

Figure 6 GNPs-treated rat received $50 \mu$ of $20 \mathrm{~nm}$ particles for 7 days demonstrating hepatic central vein intima disruption.

The GNPs-normal rat demonstrating normal hepatocytes is shown in Figure 7.

The present study demonstrates that the inflammation produced in the liver and other tissues/or organs was more prominent with smaller GNPs ones induced more affects and related with time exposure of GNPs

Additional experimental investigations related to plasma and tissues (especially liver) cytokine, histomorphologcal and ultrastrucural will be performed to cover and understand the toxicity and the potential use of GNPs as therapeutic and diagnostic tool. It has been reported that smaller GNPs caused significantly greater oxidative stress and cytotoxicity effects than larger ones [23,25].

In present study we have not measured GNPs concentration in urine and feces, but this point will be taken into our consideration in other new additional

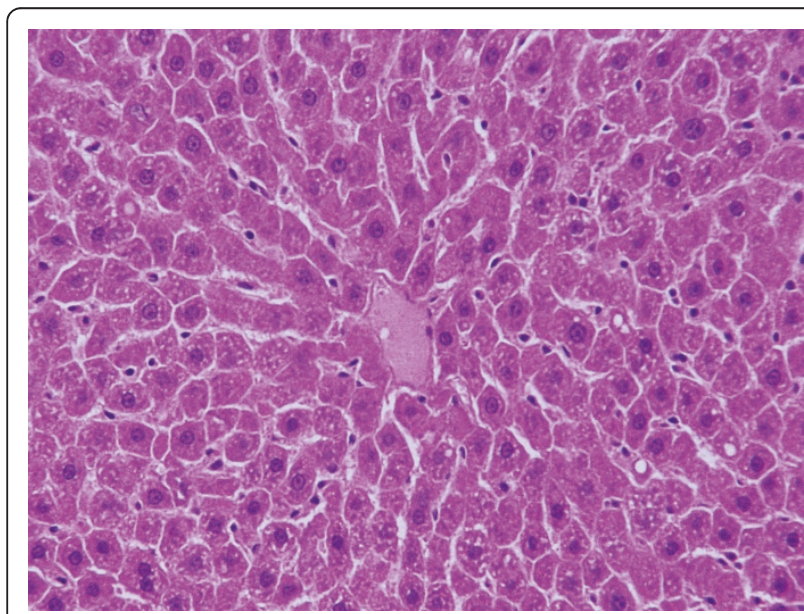

Figure 7 GNPs-normal rat demonstrating normal hepatocytes. experiments. It has been reported by Lasagna-Reeves et al., 2010 that administrated NPs were primarily taken up by liver and spleen in a large quantity and small amounts distributed in the lung, kidney, heart, and brain after single administration [26].

\section{Conclusions}

Histological alterations induced by GNPs exposure as shown in the results of the present work could be an indication of injured hepatocytes due to GNPs toxicity that became unable to deal with the accumulated residues resulting from metabolic and structural disturbances caused by these particles. One might conclude that these alterations are size-dependent with smaller ones induced more damage with relation with the time exposure of GNPs.

The appearance of hepatocytes cytoplasmic inflammatory cells infiltration, central vein intima disruption, fatty change and Kupffer cells hyperplasia may suggest that GNPs interact with proteins and enzymes of the hepatic tissue interfering with the antioxidant defense mechanism and leading to reactive oxygen species (ROS) generation which in turn may induce stress in the hepatocytes to undergo necrosis.

Additional supplementary histomorphologcal and ultrastrucural experimental investigations are needed to cover and understand the toxicity and the potential therapeutic and diagnostic use.

\section{Acknowledgements}

The author is very grateful to the National Plan of Science and Technology (NPST). This research was financially supported by the National Science and Technology Innovation Plan (NSTIP), Research No. 08-ADV206-02 and Research No. 09-NAN670-02, College of Science, King Saud University, Saudi Arabia.

\section{Author details}

'Department of Physics and Astronomy, College of Science, King Saud University, Saudi Arabia. ${ }^{2}$ College of Applied Medical Sciences, Al-Jouf University, P.O. Box (2014), Skaka - Al-Jouf, Saudi Arabia.

\section{Authors' contributions}

MAKA and BMJ have analyzed data, interpreted and written the final draft of this manuscript. The animal model used in this study was obtained from the Laboratory Animal Center (College of Pharmacy, King Saud University, Saudi Arabia). MAKA has conceived the study and its design and obtained research grants for this study. The authors have read and approved the final manuscript.

\section{Competing interests}

The authors declare that they have no competing interests.

Received: 4 July 2011 Accepted: 5 August 2011

Published: 5 August 2011

\section{References}

1. Lanone S, Boczkowski J: Biomedical applications and potential health risks of nanomaterials: molecular mechanisms. Curr Mol Med 2006, 6:651-63.

2. Yu LE, Yung L-YL, Balasubramaniam KS, Hartono D, et al: Translocation and effects of gold nanoparticles after inhalation exposure in rats. Nanotoxicology 2007, 1(3):235-42. 
3. Connor EE, Mwamuka J, Gole A, Murphy CJ, Wyatt MD: Gold nanoparticles are taken up by human cells but do not cause acute cytotoxicity. Small 2005, 1(3):325-327.

4. Takahashi H, Niidome $Y$, Niidome T, Kaneko K, Kawasaki H, Yamada S: Modification of gold nanorods using phosphatidylcholineto reduce cytotoxicity. Langmuir 2006, 22(1):2-5.

5. Pan Y, Neuss S, Leifert A, Fischler M, Wen F, Simon U, Schmid G, Brandau W, Jahnen-Dechent W: Size-dependent cytotoxicity of gold nanoparticles. Small 2007, 3(11):1941-1949.

6. MacNee W, Donaldson K: Mechanism of lung injury caused by PM10 and ultrafine particles with special reference to COPD. Eur Respir J 2003, 40:47S-51S.

7. Jia HY, Du LB, Tian $Q, Y C X$ : Potential oxidative stress of gold Nanoparticles by induced-NO releasing in serum. J am Chem Soc 2009, 131(1):40-1.

8. Chithrani BD, Chan WC: Elucidating the mechanism of cellular uptake and removal of protein-coated gold nanoparticles of different sizes and shapes. Nano Lett 2007, 7:1542-1550.

9. Pan Y, Neuss S, Leifert A, Fischler M, Wen F, Simon U, Schmid G, Brandau W, Jahnen-Dechent W: Size-dependent cytotoxicity of gold nanoparticles. Small 2007, 3:1941-1949.

10. BarathManiKanth S, Kalishwaralal K, Sriram M, Pandian SRK, Youn H, Eom S, Gurunathan G: Anti-oxidant effect of gold nanoparticles restrains hyperglycemic conditions in diabetic mice. Journal of Nanobiotechnology 2010, 8:16

11. Hussain SM, Hess KL, Gearhart JM, Geiss KT, Schlager JJ: In vitro toxicity of nanoparticles in BRL- 3A rat liver cells. Toxicol in Vitro 2005, 19:975-983.

12. Schrand AM, Bradich-Stolle LK, Schlager JJ, Dai L, Hussain SM: Can silver nanoparticles be useful as potential biological labels? Nanotechnology 2008, 9:1-13

13. Shaw SY, Westly EC, Pittet MJ, Subramanian A, Schreiber SL, Weissleder R: Perturbational profiling of nanomaterial biologic activity. Proc Natl Acad Sci USA 2008, 105:7387-7392.

14. Gibson JD, Khanal BP, Zubarev ER: Paclitaxel-functionalized gold nanoparticles. J Am Chem Soc 2007, 129:11653-11661.

15. Connor EE, Mwamuka J, Gole A, Murphy CJ, Wyatt MD: Gold nanoparticles are taken up by human cells but do not cause acute cytotoxicity. Small 2005, 1:325-327.

16. Dani RK, Kang M, Kalita M, Smith PE, Bossmann SH, Chikan V: MspA poringold nanoparticle assemblies: enhanced binding through a controlled cysteine mutation. Nano Lett 2008, 8:1229-1236.

17. Pearse AE: Histochemistry. Theoritical and applied. Analytical technology. Churchill-Livingstone, Edinburgh; 419852.

18. Del Monte U: Swelling of hepatocytes injured by oxidative stress suggests pathological changes related to macromolecular crowding. Medical Hypotheses 2005, 64(4):818-825.

19. Neyrinck A: Modulation of Kupffer cell activity: physio-pathological consequences on hepatic metabolism. Bull Mem Acad R Med Belg 2004, 159(5-6):358-66.

20. Pandey G, Srivastava DN, Madhuri S: A standard hepatotoxic model produced by paracetamol in rat. Toxicology International 2008, 15(1):69-70.

21. Johar D, Roth JC, Bay GH, Walker JN, Kroczak TJ, Los M: Inflammatory response, reactive oxygen species, programmed (necrotic-like and apoptotic) cell death and cancer. Rocz Akad Med Bialymst 2004, 49:31-9.

22. Reddy JK, Rao MS: Lipid metabolism and liver inflammation. II. Fatty liver disease and fatty acid oxidation. Am J Physiol Gastrointest Liver Physiol 2006, 290(5):G852-8

23. Tedescoa S, Doyleb H, Blascoc J, Redmondb G, Sheehana D: Oxidative stress and toxicity of gold nanoparticles in Mytilus edulis. Aquatic Toxicology 2010, 100:178-186.

24. Senaratne RH, De Silva AD, Williams SJ, Mougous JD, Reader JR, Zhang TJ, Chan S, Sidders B, Lee DH, Chan J, Bertozzi CR, Riley LW: 5'Adenosinephosphosulphate reductase $(\mathrm{CysH})$ protects Mycobacterium tuberculosis against free radicals during chronic infection phase in mice. Mol Microbiol 2006, 59:1744-1753.

25. Pan Y, Leifert A, Ruau D, Neuss S, Bornemann J, Schmid G, Wolfgang B, Ulrich S, Willi J-D: Gold nanoparticles of diameter $1.4 \mathrm{~nm}$ trigger necrosis by oxidative stress and mitochondrial damage. Small 2009, 5:2067-2076.

26. Lasagna-Reeves C, Gonzalez-Romero D, Barria MA, Olmedo I, Clos A, Sadagopa Ramanujam VM, Urayama A, Vergara L, Kogan MJ, Soto C Bioaccumulation and toxicity of gold nanoparticles after repeated administration in mice. Biochemical and Biophysical Research Communications 2010, 393:649-655.

27. Nel A, Xia T, MØdler L, Li N: Toxic potential of materials at the nanolevel. Science 2006, 311:622-627.

doi:10.1186/1476-511X-10-133

Cite this article as: Abdelhalim and Jarrar: Gold nanoparticles administration induced prominent inflammatory, central vein intima disruption, fatty change and Kupffer cells hyperplasia. Lipids in Health and Disease 2011 10:133.

\section{Submit your next manuscript to BioMed Central and take full advantage of:}

- Convenient online submission

- Thorough peer review

- No space constraints or color figure charges

- Immediate publication on acceptance

- Inclusion in PubMed, CAS, Scopus and Google Scholar

- Research which is freely available for redistribution

Submit your manuscript at www.biomedcentral.com/submit
Ciomed Central 